\title{
Knowledge and Practice on Pain Management among Nurses Working in Palliative Care Unit
}

\author{
Most. Rahima Khatun ${ }^{1 *}$, Dr. Rafaat Choudhury ${ }^{2}$, Dr. Aysha Haque ${ }^{3}$, Dr. Md. Golam Abbas ${ }^{4}$, Dr. Hafiza Sultana ${ }^{5}$, Dr.
} Mohammad Rashidul Alam ${ }^{6}$

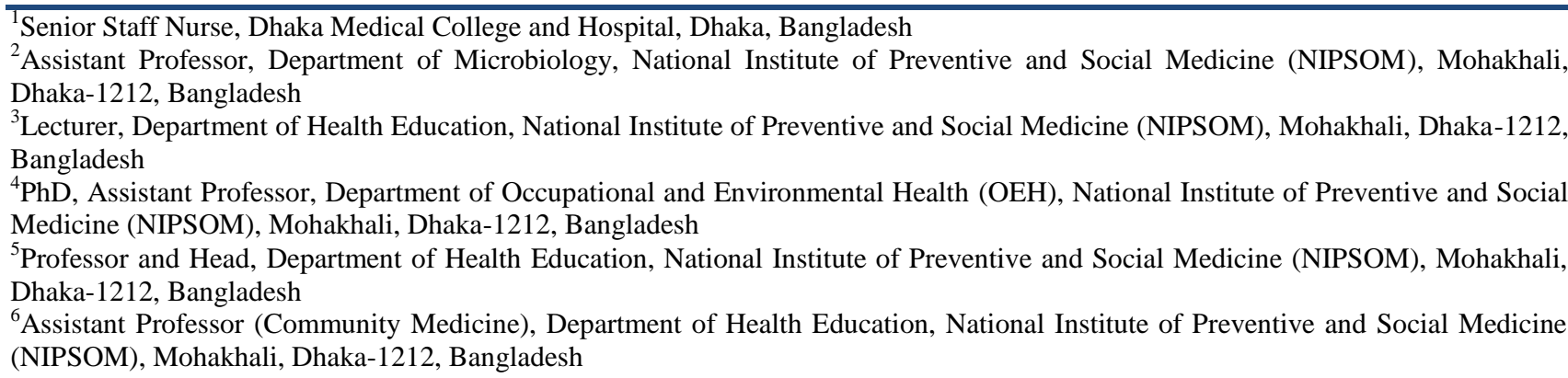
(NIPSOM), Mohakhali, Dhaka-1212, Bangladesh

\section{Article History \\ Received: 09.11.2022 \\ Accepted: 26.01.2022 \\ Published: 09.02.2022 \\ Journal homepage: \\ https://www.easpublisher.com}

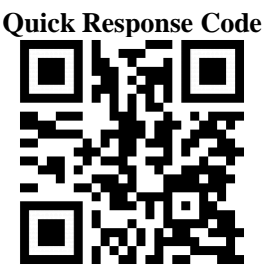

\begin{abstract}
Introduction: To provide quality care at the end of life of chronically sick patient's nurses must have good knowledge and practice about Palliative care because they are the key member of health team who typically has the greatest contact with patient's problem. When a patient enters the end stage of life threatening disease like Cancer, treatment of pain and other symptoms must be considered to preserve quality of life. Nurse's expertise is essential in providing physical and emotional care to the patient and family and in organizing the patient's environment to minimize burden and control of suffering. Nurses provide better care in all health care setting to all groups of peoples according to situation but there is scarce data on the relative field. Aim of the study: The aim of the study was to observe association of social characteristics with knowledge and practice of pain management among nurses. Methods: This descriptive cross-sectional study was conducted at the palliative care units of Dhaka Medical College Hospital (DMCH), National Institute of Cancer Research Hospital (NICRH), Bangabandhu Sheikh Mujib Medical University (BSMMU), and Ahsania Mission Cancer \& General Hospital, Dhaka. The study duration was one year, from 1st January to 31st December, 2020. The study was conducted with a total of 112 nurses working at the palliative care Units of the study hospitals. Result: Among the participants, the mean age was $29.79,( \pm \mathrm{SD} 6.075)$, and majority were from the age group of $21-30$ years. $88.4 \%$ were female $74.1 \%$ were graduates, $47 \%$ received training on pain management, $68.8 \%$ worked in government hospitals, $74.1 \%$ had less than 5 years of working experience. No significant association was observed between knowledge and social characteristics. The practice level of nurses was significantly associated with Age $(p=0.03)$ and Training $(p=0.01)$. Conclusion: The Palliative Care pain management aims to maximize the quality of life of patients suffering from life-limiting diseases. In this study majority of nurses had good knowledge however good practice was seen in relatively less number of nurses. The nurse's lack of adequate training in Palliative care pain management was one of the causes of suffering of patients. Keywords: Palliative, Cancer, pain, Knowledge, Practice.
\end{abstract}

Copyright (C) 2022 The Author(s): This is an open-access article distributed under the terms of the Creative Commons Attribution 4.0 International License (CC BY-NC 4.0) which permits unrestricted use, distribution, and reproduction in any medium for non-commercial use provided the original author and source are credited.

\section{INTRODUCTION}

The basic concepts of Palliative care were developed between 1960 and 1990, mainly in the field of oncology. Palliative care is a term that comes from Latin 'Pallium' which means "a clock" and refers to specialized medical for Patient with severely ill. It is focused on providing patient with relief from the symptoms, pain, and stress of a serious illness and allows them to lead a better life at the end of life [1]. The term "Palliative care" is increasingly used concerning diseases other than cancer such as chronic progressive pulmonary disorders, chronic renal diseases (CRD), chronic heart failure (CHF), HIV/AIDS, progressive neurological condition, sever non-

*Corresponding Author: Most. Rahima Khatun 
communicable diseases (NCD), Alzheimer's and other dementias, cirrhosis of liver CLD), diabetes, multiple sclerosis, Parkinson's disease, rheumatoid arthritis, drug-resistant tuberculosis, Schizophrenia, congenital anomalies, Meningitis, blood and immune disorder and also older people [2]. It has been conventionally attributed to a variety of obstacles including Nurses, patients and health care system concerns. In developing countries, recently Palliative care is increasing because more people are living longer, often with complex needs as a consequence of chronic illness or cancer over long periods [3]. The purpose of palliative care is that patients should receive high-quality care, regardless of the illness or service received. To provide quality care at the end of life of chronically sick patient's nurses must have good knowledge and practice about Palliative care because they are the key member of health team who typically has the greatest contact with patient's problem. When a patient enters the end stage of life threatening disease like Cancer, treatment of pain and other symptoms must be considered to preserve quality of life. Nurse's expertise is essential in providing physical and emotional care to the patient and family and in organizing the patient's environment to minimize burden and control of suffering. Nurses provide better care in all health care setting to all groups of peoples according to situation but there is scarce data on the relative field. According to the research by NIPORT (2014), it was identified that there is gap in knowledge about pain assessment and documentation, inability to assess pain, and poor communication between the patient and the health care provider which lead to ineffective pain management [4]. A nurse is a key person who can improve the quality of pain management and who can provide nursing care sufficiently to meet the patient needs. Nurses with stronger knowledge and practice lead to better Pain assessment \& documentation, to improved outcomes and higher patient satisfaction scores. In clinical settings, nurses play a vital role in pain management and must be knowledgeable regarding how to best assess and manage the pain. Inadequate pain management has shown to affect patient outcomes by potentially increasing hospital stay and delaying recovery; thus, the management of pain has major implications for nursing. This can affect patients physiological, and health safety. However, many nurses in general practice settings lack the knowledge about basic pain management principles, this also applies to the practice that nurses have towards pain and its assessment [5]. Pain management is an important aspect in the palliative care patients. Although palliative care pain can be controlled up to $90 \%$ of the cases through the use of appropriate methods, its prevalence has been reported to be as high as $64 \%$ among patients with advanced cancer and pain control was found to be in adequate for more than $40 \%$ of patients [6].

\section{OBJECTIVE \\ General Objective}

- To observe the knowledge and practice of pain management among nurses working in the palliative care unit

\section{Specific Objectives}

- To observe the association between social demographic and the knowledge and practice of pain management

\section{METHODS}

This descriptive cross-sectional study was conducted at the palliative care units of Dhaka Medical College Hospital (DMCH), National Institute of Cancer Research Hospital (NICRH), Bangabandhu Sheikh Mujib Medical University (BSMMU), and Ahsania Mission Cancer \& General Hospital, Dhaka. The study duration was one year, from $1^{\text {st }}$ January to $31^{\text {st }}$ December, 2020. The study was conducted with a total of 112 nurses working at the palliative care Units of the study hospitals. Purposive type of non-probability sampling technique was applied for selection of the study participants. A semi-structured questionnaire was prepared according to the objective \& variables of the study. For the assessment of the level of knowledge and practice on pain management among nurses working in the Palliative care units, a pre-tested semi- structured questionnaire was used. Ethical clearance of the study was obtained from the Institutional Review Board (IRB), NIPSOM, under BSMMU. Permission from the concerned authority of the selected institutes was taken prior to data collection. Prior to starting the collection of information, written informed consent was obtained from each of the selected research respondents. Following the questionnaire collection, face to face interview was taken for each respondent separately in maintaining privacy and confidentiality strictly.

\section{Inclusion Criteria}

All nurses working in the Palliative Care Units having at least six months' experience of working in Palliative Care Units and willing to participate were included in the study.

\section{Exclusion Criteria}

Nurses working in administration and student nurses were excluded from the study.

\section{Results}

Among 112 nurses, the mean age was 29.79, $( \pm$ SD 6.075$)$. Most of the nurses $(68.8 \%)$ were within the age range of 21-30 years and only $9(8.0 \%)$ nurses within the age range of $41-50$ years. Figure 1 shows that out of 112 respondents $99(88.4 \%)$ were female and $13(11.6 \%)$ were male. Figure 2 shows that among of the 112 nurses' $83(74.1 \%)$ completed graduation in nursing and $29(25.9 \%)$ were post graduate in nursing. 
The figure 4 pie diagram shows that among of 112 nurses 53(47.3\%) received pain management training on Palliative care and $59(52.7 \%)$ did not receive any training. Among the participants, $74.1 \%$ had less than 5 years of experience, while $25.9 \%$ had at least 5 years of experience. $47.3 \%$ received practice regarding care in the palliative care unit on pain management, while $52.7 \%$ didn't receive any training. $68 \%$ of the participants were working on government hospitals, $10.7 \%$ in private hospital, and $20.5 \%$ were working in autonomous hospitals. The above table shows association between knowledge level and sociodemographic variables. No Statistically significant association was found with age $(\mathrm{p}=0.51)$, gender $(\mathrm{p}=0.35)$, educational qualification $(\mathrm{p}=0.80)$, working experience $(\mathrm{p}=0.22)$ and Training $(\mathrm{p}=0.45)$ with knowledge. The table shows that practice level of nurses was significantly associated with Age $(p=0.03)$ and Training $(\mathrm{p}=0.01)$.

Table-1: Distribution of the nurses by age

\begin{tabular}{|l|l|l|}
\hline Age group(years) & Number (n) & Percentage (\%) \\
\hline $21-30$ & 77 & $68.8 \%$ \\
\hline $31-40$ & 26 & $23.2 \%$ \\
\hline $41-50$ & 9 & $8.0 \%$ \\
\hline Total & $\mathbf{1 1 2}$ & $\mathbf{1 0 0 \%}$ \\
\hline Mean \& SD & $29.79 \pm 6.075$ & \multicolumn{1}{|l}{} \\
\hline
\end{tabular}

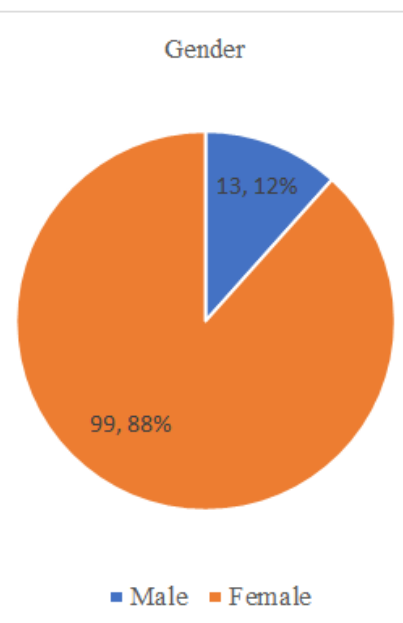

Fig-1: Distribution of nurses according to gender

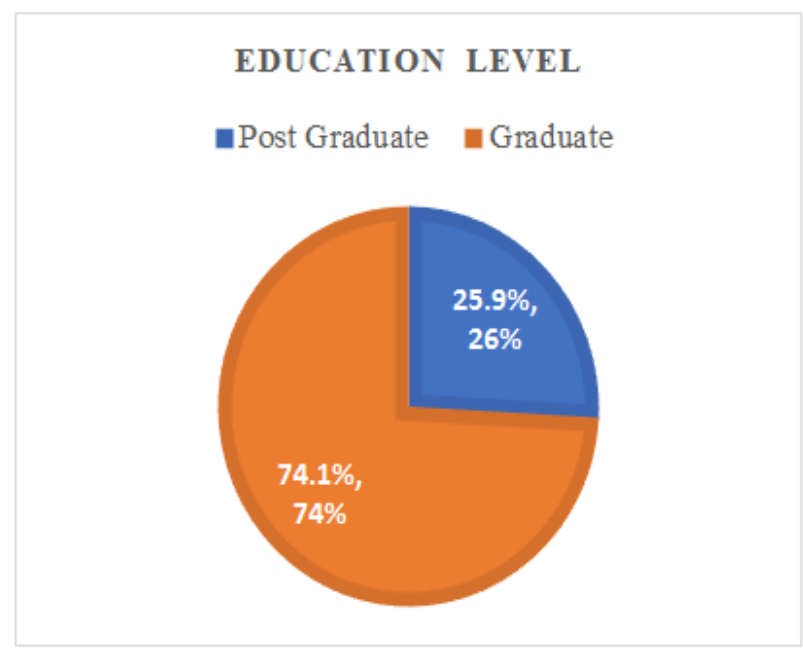

Fig-2: Distribution of nurses by professional qualification

\section{Training on Pain Management}

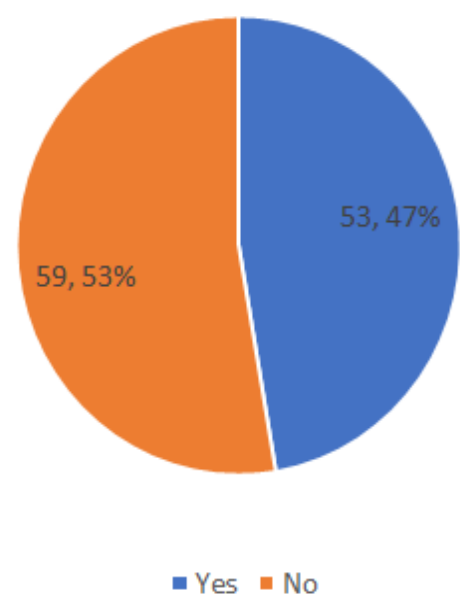

Fig-3: Distribution of nurses on the basis of training received on Pain management $(n=112)$

Table-2: Distribution of the nurses' by socio-demographic variables

\begin{tabular}{|l|l|l|l|}
\hline \multicolumn{2}{|l|}{ Name of variables } & Number (n) & Percentage (\%) \\
\hline \multirow{2}{*}{ Experience } & $<5$ Years & 83 & $74.1 \%$ \\
\cline { 2 - 4 } & $\geq 5$ Years & 29 & $25.9 \%$ \\
\hline \multirow{2}{*}{ Training } & Yes & 53 & $47.3 \%$ \\
\cline { 2 - 4 } & No & 59 & $52.7 \%$ \\
\hline \multirow{2}{*}{$\begin{array}{l}\text { Working } \\
\text { Place }\end{array}$} & Government & 77 & $68.8 \%$ \\
\cline { 2 - 4 } & Autonomous & 23 & $20.5 \%$ \\
\cline { 2 - 4 } & Private & 12 & $10.7 \%$ \\
\hline
\end{tabular}


Most. Rahima Khatun et al., EAS J Nurs Midwifery; Vol-4, Iss-1 (Jan-Feb -2022): 16-20

Table-3: Association between knowledge level regarding Palliative Care pain management and Sociodemographic characteristics of nurses' (n -112)

\begin{tabular}{|c|c|c|c|c|c|}
\hline \multirow{2}{*}{\multicolumn{2}{|c|}{ Name of variables }} & \multicolumn{3}{|c|}{ Knowledge Level } & \multirow[b]{2}{*}{$\begin{array}{l}\text { Chi-Square } \\
\text { Test }\end{array}$} \\
\hline & & $\begin{array}{l}\text { Poor } \\
\text { knowledge }\end{array}$ & $\begin{array}{l}\text { Good } \\
\text { Knowledge }\end{array}$ & Total & \\
\hline \multirow{3}{*}{ Age (Years) } & $21-30$ & $20(26.0 \%)$ & $57(74.0 \%)$ & $77(100 \%)$ & \multirow{3}{*}{$\mathrm{P}=0.51$} \\
\hline & $31-40$ & $08(30.8 \%)$ & $18(69.2 \%)$ & $26(100 \%)$ & \\
\hline & $41-50$ & $01(11.1 \%)$ & $08(88.9 \%)$ & $9(100 \%)$ & \\
\hline \multirow{2}{*}{ Gender } & Male & $02(15.4 \%)$ & $11(84.6 \%)$ & $13(100 \%)$ & \multirow{2}{*}{$\mathrm{P}=0.35$} \\
\hline & Female & $27(27.3 \%)$ & $72(72.7 \%)$ & $99(100 \%)$ & \\
\hline \multirow{2}{*}{$\begin{array}{l}\text { Educational } \\
\text { Qualification }\end{array}$} & Graduate & $21(25.3 \%)$ & $62(74.7 \%)$ & $83(100 \%)$ & \multirow{2}{*}{$\mathrm{P}=0.80$} \\
\hline & Post- graduate & $08(27.6 \%)$ & $21(72.4 \%)$ & $29(100 \%)$ & \\
\hline \multirow{2}{*}{ Working Experience } & $>5$ & $19(22.9 \%)$ & $64(77.1 \%)$ & $83(100 \%)$ & \multirow{2}{*}{$\mathrm{P}=0.22$} \\
\hline & $<5$ & $10(34.5 \%)$ & $19(65.5 \%)$ & $29(100 \%)$ & \\
\hline \multirow{2}{*}{ Training } & Yes & $12(22.6 \%)$ & $41(77.4 \%)$ & $53(100 \%)$ & \multirow{2}{*}{$\mathrm{P}=0.45$} \\
\hline & No & $17(28.8 \%)$ & $42(71.2 \%)$ & $59(100 \%)$ & \\
\hline
\end{tabular}

Table-4: Association between level of practice on pain management and socio-demographic characteristics of nurses' (n-112).

\begin{tabular}{|c|c|c|c|c|c|c|}
\hline \multirow{2}{*}{\multicolumn{2}{|c|}{ Variable }} & \multicolumn{4}{|c|}{ Practice Level } & \multirow{2}{*}{ P-value } \\
\hline & & Inadequate & Moderate & Adequate & Total & \\
\hline \multirow{3}{*}{ Age (Years) } & $21-30$ & $14(18.2 \%)$ & $13(16.9 \%)$ & $50(64.9 \%)$ & $77(100 \%)$ & \multirow{3}{*}{0.03} \\
\hline & $31-40$ & $01(3.8 \%)$ & $10(38.5 \%)$ & $15(57.7 \%)$ & $26(100 \%)$ & \\
\hline & $41-50$ & $02(22.2 \%)$ & $0(0.0 \%)$ & $07(77.8 \%)$ & $9(100 \%)$ & \\
\hline \multirow{2}{*}{ Gender } & Male & $02(15.4 \%)$ & $3(23.1 \%)$ & $08(61.5 \%)$ & $13(100 \%)$ & \multirow{2}{*}{0.91} \\
\hline & Female & $15(15.2 \%)$ & $20(20.2 \%)$ & $64(64.6 \%)$ & $99(100 \%)$ & \\
\hline \multirow{2}{*}{$\begin{array}{l}\text { Educational } \\
\text { Qualification }\end{array}$} & Graduate & $10(12.0 \%)$ & $16(19.3 \%)$ & $57(68.7 \%)$ & $83(100 \%)$ & \multirow{2}{*}{0.19} \\
\hline & Post- graduate & $07(24.1 \%)$ & $07(24.1 \%)$ & $15(51.8 \%)$ & $29(100 \%)$ & \\
\hline \multirow{2}{*}{$\begin{array}{l}=\text { Working } \\
\text { Experience }\end{array}$} & $>5$ & $09(10.8 \%)$ & $19(22.9 \%$ & $55(66.3 \%)$ & $83(100 \%)$ & \multirow{2}{*}{0.08} \\
\hline & $<5$ & $08(27.6 \%)$ & $04(13.8 \%)$ & $17(58.6 \%)$ & $29(100 \%)$ & \\
\hline \multirow{2}{*}{ Training } & Yes & $04(7.5 \%)$ & $08(15.1 \%)$ & $41(77.4 \%)$ & $53(100 \%)$ & \multirow{2}{*}{0.01} \\
\hline & No & $13(22.0 \%)$ & $15(25.5 \%)$ & $31(52.5 \%)$ & $59(100 \%)$ & \\
\hline
\end{tabular}

\section{DISCUSSION}

The study intended to find out the knowledge and practice on pain management among nurses working in Palliative Care Units in selected hospitals of Dhaka city, and their association with age, Sex, professional qualification, working place, experiences and training on pain management. The current study revealed that, the majority of the nurses $68.8 \%$ (77), where between the age group of 21-30 years, and very few nurses were over the age of 40 . This was similar to the findings of multiple other similar studies [7-10]. In the present study, $88.4 \%$ of the nurses were female and only $11.6 \%$ were male. This was supported by the general reality all over the world, that nursing is mostly a female oriented job. This was, however, different from the findings of a Chinese study, where male and female prevalence was similar among nurses [11, 12]. Qadre and Alkhalaieh observed higher male prevalence in their study, which was conducted in Jordan, one of the more conservative countries of the world [7]. The present study showed that out of 112 nurses $74.1 \%$ were graduate nurses and $25.9 \%$ were post-graduate nurses. Similarly, in Bangladesh a study in private hospital found that under graduate nurse were $59.5 \%$, graduate nurse $25.0 \%$, and post-graduate nurse $15.5 \%$ [9].
Regarding working experience in the present study, majority of nurses $(74 \%)$ had working experience of less than 5 years and rest of the nurses (26\%) had experience of more than 5 years. This was completely contradicting to the findings of another Bangladeshi study, where the majority of nurses $(79 \%)$ had more than 5 years of working experience [9]. These findings were however, similar to a 2014 study conducted at Cairo [13]. Specific training of nurses on management of palliative pain may enhance quality of palliative care. In this study among 112 nurses, $47.3 \%$ nurses received training on Palliative care pain management and $52.7 \%$ did not receive any training. This was much better compared to few other studies where the ratio of participants who received training went below $30 \%$ [12, 13]. A 2018 study conducted in Uganda showed much better ratios, where $89.6 \%$ had received training [14]. $68.8 \%$ of the present study participants worked in govt. hospitals, $10.7 \%$ in private hospital and $20.5 \%$ nurses worked in Autonomous hospitals. This was similar to the findings of Samara et al. [15] The present study recorded the knowledge of the nurses regarding factors such as pain management, pain grading, use of NSAIDS with measurements, risk of addiction to medicine, and such factors were correlated with the social- 
demographic characteristics of the nurses. Similar correlation was done regarding practice of various factors with sociodemographic characteristics of the nurses. In the knowledge sector, good knowledge was observed in almost all sectors, but no statistical significance was observed between knowledge and sociodemographic characteristics. In the practice section, however, significance was observed between practice levels and age groups. Adequate practice was observed in majority of the participants of all age groups, but inadequate level of practice had higher prevalence in the oldest age group. Similarly, significance was also observed in practice levels and training. Moderate and adequate practice had high prevalence among those who received training, while inadequate level of practice was much higher among participants who did not received training, compared to those who did. Similar significance was observed between practice and working experience in the study of Morsy et al. [13]

\section{Limitations of the Study}

The study was conducted with a small sample size and in a short study period. Purposive sampling was applied so there was a chance of bias during data collection. Knowledge of all the domains of the pain management in Palliative Care Units was not assessed in this study.

\section{CONCLUSION \& RECOMMENDATION}

The Palliative Care pain management aims to maximize the quality of life of patients suffering from life-limiting diseases. In this study majority of nurses had good knowledge however good practice was seen in relatively less number of nurses. The nurse's lack of adequate training in Palliative care pain management was one of the causes of suffering of patients. To improve adequate practice of palliative care nurses hands on training should be given on pain management by pharmacological and non- pharmacological methods and documentation. Adequate training of nurses is necessary to improve quality care to dying people.

\section{REFERENCES}

1. Das, G. A., \& Haseena, T. A. (2013). Knowledge and Attitude of Staff Nurses Regarding Palliative Care. International Journal of Science and Research, 4(11).

2. National Institute of Population Research and Training, (2014).

3. World Health Organization. (2006). WHO definition of Palliative Care. Available from:http://www.who.int/cancer/palliative/definitio n/en/
4. Pasero, C., Li, P. D., Gilbent, H. E., Medina, J., Sessler, C. N. (2009)." Structured approaches to pain management in the ICU," Journal of Chest, 135(6), 1665- 1672.

5. Kiwanuka, F., \& Masaba, R. (2018). "Nurses' Knowledge, attitude and practice regarding pain assessment among patients with Cancer. Journal of Analytical Research in Clinical Medicine, 6(2), 7279

6. Jho H. J., Kim, Y., Kong, K. A., Kim, D.H., Choi, J. Y., Nam, E. J., Koh, S., Hwang, K. O., Back, S. K., Park, E. J. (2014). Knowledge, practice, and perceived barriers regarding Cancer pain management among physicians and nurses in Korea. PLoS ONE., 9(8), 1-7

7. Qadre, M. Al., \& Khalaileh, M. Al., (2012). Jordanian Nurses Knowledge and Attitude Regarding pain management. Journal of Pain Management Nursing, 15, 220-228.

8. Karkada, S., Nayak, S. B., Malathi. (2011). Awareness of Palliative care among diploma nursing students. Indian Journal of Palliative Care, 17(1), 20-23.

9. Mondol, S., Muhammad, F., \& Chowdhury, A. A. (2018). Nurses' knowledge and practices related to pain assessment in critically ill patients in a selected private hospital in Bangladesh. International Journal of Community Medicine and Public Health, 5(10), 4219-4224.

10. Begum, S., \& Khanam, M. (2015). Knowledge and Practice of staff Nurses on Palliative Care. Journal of JHRMLP, 1(2), 41-45.

11. Zhang, Q., Yu. C. MD., Feng. S. MD., Yao. W. MD., Shi. H. MD., Zhao, Y., Wang, Y. MD. (2015). Cancer pain \& Palliative Care section. Journal of pain Medicine, 16, 2195-2203.

12. Abudhari, G., Zahreddine, H., Hazeim, H., Assi, M. AL., Emara, S. (2014). Knowledge of and attitudes towards Palliative care among multinational nurses in Saudi Arabia. International Journal of Palliative Nursing, 20(9), 1-18.

13. Morsy, W.Y.M., Elfeky, H.A., Mohammed, S.E. (2014). Nurses Knowledge and Practices about Palliatve Care among Cancer Patient in a University Hospital Egypt. Advances in Life Science and Technology, 24, 100-113.

14. Kiwanuka, F., \& Masaba, R. (2018). "Nurses' Knowledge, attitude and practice regarding pain assessment among patients with Cancer. Journal of Analytical Research in Clinical Medicine, 6(2), 7279

15. Samara, A. M., Toba, H. A., \& Zyoud, S. H. (2018). Physicians Knowledge, perceived barriers and Practices regarding Cancer Pain management. Journal of Applied Cancer Research, 38(15), 1-8.

Cite This Article: Most. Rahima Khatun, Dr. Rafaat Choudhury, Dr. Aysha Haque, Dr. Md. Golam Abbas, Dr. Hafiza Sultana, Dr. Mohammad Rashidul Alam (2022). Knowledge and Practice on Pain Management among Nurses Working in Palliative Care Unit. EAS J Nurs Midwifery, 4(1), 16-20. 